\title{
9 Rogue Rhetorical Actors: Scientists and the Social Action of Tweeting
}

\begin{abstract}
This chapter provides a case study of scientists on Twitter as a way to examine how well-intentioned and rhetorically-reasonable responses to a rhetorical situation can be confused by multiple intersecting, constantly unfolding, and often conflating rhetorical situations, genre users, and genres. The case explores conversations that erupted after several federal science-related agencies in the United States received a gag order. Resisting such silencing, several "rogue” or "alternative government" accounts appeared on Twitter, and those accounts began sharing information about climate change. More broadly, these accounts entered a political debate, taking a position on the perceived political moment. We also uncover challenges to how we theorize about genre as we move from well-established genres of science communication to public or vernacular genres. Genre theory can help us understand how what appear to be reasonable rhetorical strategies may in fact serve to undermine one's argument. In the case of tweeting scientists, we suggest that scientists deploy typified responses to share science or defend science, but the rhetorical situation that opponents respond to is one designed to generate uncertainty in science, in the authorities or experts that report science to us, and in the very institutions that support their research.
\end{abstract}

\subsection{Introduction}

Rhetorical genre theory provides an important tool for understanding the possibilities for rhetorical response and, thus, social action (Miller, 1984). Often rhetorical genre theorists chart how genres shape particular responses to a rhetorical situation, describing not only form and rhetorical conditions for a genre's use, but also the norms and values that genres embody. Understanding the norms and values that genres mark is important because they provide insight into the motivation of genre users. Commonly genre theorists examine those genres that are relatively stabilized (Schryer, 1993) and that are embedded in professional communities. When studying well-stabilized, professional genres, understanding the norms and values of a genre can tell us something of the broader community of genre users. For example, when we investigate genres of science, we can learn something about the norms of science as a profession and the values that scientists hold, such as objectivity in research by the way that scientific research articles are crafted (Bazerman, 1988). Recently, however, genre theorists have also turned their attention to what Miller (2017) has called "vernacular genres," those that take place in public discourse (see, leading these efforts, 
Reiff \& Barwarshi, 2016). Such work is an important area for genre scholarship, and pushes further how we characterize genre knowledge, interpretation, and use. Somewhere between those professional and vernacular genres, there are genres that operate in both spheres of discourse simultaneously, and this is particularly true in the case of scientific discourse in new media environments (Kelly \& Miller, 2016). In this chapter, we investigate one example of where professional spheres of discourse meet public spheres of discourse online. Specifically, we look to climate change discourse on the microblogging platform Twitter. Climate change has become a highly politicized issue (see PEW, 2016a), and while the science has largely agreed upon its cause, the public debate about anthropogenic climate change continues. Scientists continue to weigh in on the public debate, trying to clear up misconceptions or explain the science, but the debate remains fraught. Choosing a specific site to explore how these discourses are enacted is important because, across a variety of media, we are certain to find different forms of public debate about climate change. For example, some public debates may centre on whether or not anthropogenic climate change is occurring at all, whereas others may focus on what needs to be done in response to the pending consequences of climate change. Other public debates might even engage with scientific discourse about climate change.

Our case in this chapter, too, involves a situation where scientists, publics, and policy makers engage in conversation about climate change. The case explores a particular thread of the conversation that erupted after several federal agencies in the United States received a gag order. Resisting such silencing, several "rogue" or "alternative government" accounts appeared on Twitter, ${ }^{1}$ and those accounts began sharing information about climate change. More broadly, these accounts entered a political debate, taking a position on the perceived political moment. ${ }^{2}$

But the story that follows, from the activities of scientists to the public debates and media coverage that came after, reveal a complicated landscape for communication of climate change research. Online debate about climate change would be too simple a description of what is occurring. Debates about climate change suggest more interplay between what Smart (2016) has usefully characterized as discourse coalitions of Advocates and Skeptics. Smart defines a discourse coalition as "a cluster of social actors - individuals, organizations, institutions - who, within the context of

1 Although Facebook retains the largest share of online users (68\% as of January 2018), some $24 \%$ of global online users are on Twitter, with $21 \%$ of online American users on the site, and among the American sample, users are younger, educated, and the platform is also popular among those with high incomes (PEW, 2016b, 2017, 2018).

2 Mellon and Prosser's (2017) study of British online users found that social media users' demographics tend to signal certain characteristics of their political leanings, notably they are more liberal, more politically aware, although less active insomuch as they are less likely to vote than their offline counterparts. Most significantly, what we know about social media users is that they depart from the broader public in terms of political engagement (Mellon \& Prosser, 2017, 3). 
a major social debate, are attracted to a common set of arguments” (Smart, 2016, 4). Importantly, a particular discourse coalition is defined by its opposition in an effort to achieve "discursive hegemony" (4). No doubt, these discourse coalitions remain active and engaged (see Smart \& Falconer, this volume), but climate change is also metonymic to a broader social debate. The climate change debate is a partisan issue in the United States and in many other countries, and the lines drawn are not particularly attendant to climate sciences - that is, its epistemological grounding, or, even, its axiological commitments - but instead focus on climate science as a locus of tension between partisan norms and values. Disentangling the debates that scientists are having from partisan political debates is important because they mark different rhetorical situations. Because the rhetorical situations to which these parties respond are different, the genres they use to respond to these situations necessarily differ, too. As Smart (2016) argues, the discourse coalitions in the texts surrounding the climate change debate appear to offer incommensurate views of climate change knowledge and science (14).

What we are suggesting is that this is due, in part, to the seemingly similar genres and genre sets that each coalition invokes to respond to markedly different rhetorical situations. Moreover, we suggest it is not always clear when there are multiple rhetorical situations and multiple typified responses because they may appear similar while serving different social actions. Although scientists are fighting back against false claims about the science of climate change on Twitter, showing that they are indeed rhetorically savvy in new media environments, they also appear to rely too deeply on a sincere belief about the commitment to authenticity of deliberation in this space. Where the genres deployed by scientists on Twitter to fight back were designed to establish the preeminence of science over partisan politics, an inversion occurred, and the genre activities now function as a tool of partisan resistance, with science subsumed into the political melee.

In brief, we examine this case of scientists on Twitter as a way to examine how seemingly well-intentioned and rhetorically-reasonable responses to a rhetorical situation can be confused by multiple intersecting, constantly unfolding, and often conflating rhetorical situations, genre users, and genres. Along the way, we also uncover some challenges to how we theorize about genre as we move from well-established genres of science communication to public or vernacular genres. Genre theory can help us understand how what appear to be reasonable rhetorical strategies may in fact serve to undermine one's argument. In the case of tweeting scientists, we suggest that scientists deploy typified responses to share science or defend science, but the rhetorical situation that opponents respond to is one designed to generate uncertainty in science, in the authorities or experts that report science to us, and in the very institutions that support their research. Our genres for communicating research, including climate change research, must then better attend to the complexity of the discourse spaces we are entering by returning to that old question of the rhetorical situation - or situations. 


\subsection{Genre, New Media, and Muddled Arguments}

Rhetorical genre scholars have been studying new media forms and their effect on genres for several decades now. Consider Yates and Orlikowski's (1992) important contribution theorizing genres of organizational communication, integrating genre into organizational communication studies as a concept to assist in understanding structuration processes (see, on structuration theory, Giddens, 1984). Although they acknowledge the role of new media forms, it is useful to remember that, still, genres are "enacted through rules" and that the "ways in which these genre rules influence the generation of specific communication is central to an understanding of genre as enacted within communities" (Yates \& Orlikowski, 1992, 392). Those rules include social and professional norms, as well as being "standardized by being embedded in a medium" (392). All of this is reasonably well ordered, and we can see how it is distinct from vernacular spheres and new media forms. Reiff and Bawarshi's (2016) call to attend to public genres is an important contribution to genre studies, urging genre scholars to look beyond professional discourse spheres to the rich vernacular spheres of discourse that many of us inhabit every day. As new media environments unfolding online create opportunities for new forms of engagement, particularly across different spheres of discourse, it becomes increasingly important to attend to how vernacular genres operate differently than professional genres. Genre theorists have indeed begun to investigate the manner in which new media in our complex web-based ecologies might shape genres or genre (e.g., Andersen \& van Leeuwen, 2017; Caple \& Knox, 2017; Lewis, 2016; Miller \& Shepherd, 2004, 2009; Pflugfelder, 2017; Sherlock, 2009; Smart, 2016; Wickman, 2016; Zappavigna \& Zhao, 2017; see also two volumes: Giltrow \& Stein, 2009; Miller \& Kelly, 2017).

What is illustrative in efforts to map emerging genres in new media environments is both the rapid evolution of those genres as well as how the genre users put the new media affordances and typifications to work for their particular purposes. Further, these new media environments encompass both professional discourses as well as vernacular discourses. In the latter case, digital, web-based new media provide an important case for investigation because these spaces reconfigure social interactions. As Andersen (2016) explains, "we, as members of the public, audiences, citizens, private persons, searchers, or users are confronted with structured collections of items in a more direct way than we may be used to because one means of communication employed by society's social and cultural institutions is digital networked media and their affordances" (n.p.). Rapid interplay of uptakes across discourse communities creates interesting problems for how we theorize web-based new media genres as well as how we enact them for social action, following Devitt's call in this volume.

But we wish to raise here the question of how to explore genres for social action (following Devitt) in discourses and media spaces where heterogeneous audiences and complex information environments shape and are shaped by rapidly evolving technologies and norms. Put simply, how does one assess the situation to which 
they intend to respond when the situation itself is changing, along with most of the other variables in the constellation that forms a genre? Although genre theorists have attended to these questions, we wish to add another layer in our analysis, which is how to respond if the conditions of discourse are not clear or entirely honest. To better explain what we mean, we turn to rhetorical scholar Leah Ceccarelli's (2011) recent work on manufactured scientific controversies, which has important implications for how we theorize communication of climate change research (see, also, Oreskes, 2010; Supran \& Oreskes, 2017). Chiefly, Ceccarelli's study of several cases where "scientific debate" was intentionally manufactured for political ends, intentionally misleading broader publics about the state of consensus among scientists about current research. "A scientific controversy is 'manufactured' in the public sphere," Ceccarelli explains, "when an arguer announces that there is an ongoing scientific debate in the technical sphere about a matter for which there is actually an overwhelming scientific consensus" (196). Continuing, she writes, "manufactured scientific controversy can be seen as a special type of 'public scientific controversy' in which 'strategically distorted communication' works to corrode the democratic process” (196) and, we might add, the scientific process of knowledge making and shared understanding. Climate change is among the cases she explores, recounting Frank Luntz's 2002 memo in the United States that helped change strategies around climate change discourse to sow dissent. In that memo, Luntz put it quite simply: "Voters believe that there is no consensus about global warming within the scientific community. Should the public come to believe that the scientific issues are settled, their views about global warming will change accordingly" (qtd. in Burkeman, 2003). The takeaway is that because of strategic efforts what was once a technical debate among experts was moved into an open, public debate, where all citizens have a stake and a voice, and, it follows, a framing of any attempt to argue with the public's right to engage in the debate as “elitist and antidemocratic" (Ceccarelli, 2011, 208).

Manufactured scientific controversies have important implications for how we understand the communication of research as it moves across the spectrum of genres from professional or expert genres to public or non-expert genres. Smart's (2016) work on discourse coalitions in climate change research blogs explores a debate that has been designed to result in, as he found, necessarily incommensurate beliefs about the research because the discourse coalitions are in fact arguing for broader claims than the particular research findings themselves. Thus, some arguments are about scientific epistemology and others forward axiological claims.

Indeed, moving the debate to new genres allows for the debate itself to be moved. In the pages of research articles, scientists debate with a set of norms and conventions rooted in their particular disciplinary homes and in scientific discourse in general. In these pages, debates are not large-scale ideological issues but, rather, specific aspects of a scientific problem. Meta-studies or review articles reporting on consensus of these papers, too, adhere to the norms of disciplines, including how the findings are assessed and how they contribute toward a common understanding for the particular 
scientific community. Such work represents a complex assessment of data specific to particular scientific questions. Consensus among scientists that climate change is indeed happening and has anthropogenic causes comes from immersion in one's own field, reviewing the evidence and arguments within a scientific framework, and from broader engagement in the multidisciplinary climate research community (Oreskes, 2004). Genres used in the internal communication of climate research among scientists necessarily serve different functions and purposes than more public genres. Specifically, the professional genres used to communicate climate science among climate researchers are designed for assessing, understanding, and vetting research.

Public genres serve different purposes, and, further, afford the possibility of reformulating the argument. Fahnestock's (1986) Accommodating Science makes this point well, detailing how arguments in public genres may take a different form to address the interest and needs of the audience. For example, a research article will have a specific argument crafted for a disciplinary conversation, but as that research moves into more public, non-expert domains, the argument might move from an appeal to producing disciplinary knowledge to an appeal to the wonder of the research itself. Normally, we might see this kind of reformulation as an important step toward connecting with a different audience which, presumably, has their own interests and should indeed be accommodated by thoughtful communicators attempting to share complex knowledge with broader publics. However, after Ceccarelli's work on manufactured controversies, it is not difficult to see how this movement across genres affords a moment where research can be intentionally distorted. For example, this movement across genres often requires change in how an argument is made or even a change in the argument itself, as Fahnestock's examples of accommodated science demonstrate. Indeed, such a movement could even divert the argument from epistemological claims about research findings to axiological claims only superficially related to the science. Even minor changes to an argument, such as emphasizing the funding support for a research study, can shift the framing of the argument from a question of science to questions about, for instance, financial influence. Practically, the consequences of such genre movement are highly significant to how we communicate climate change research.

Determining when these changes to argument have occurred is challenging because we bring to bear our own understandings of genre and frames of reference to assess and interpret the rhetorical situation we are encountering. Genre studies acknowledge that genres play a regulative function, shaping how we understand text in context, and that regulative function affects how we interpret a situation. Auken (2015) examines the too often overlooked aspects of genre interpretation, including genres' regulative function, which he notes is fragile, saying that "regulations imposed by genre can be broken at a moment's notice or made the subject of manipulation or interpretation" (159). One outcome of this "break" is that a new genre may "move into ... an entirely different genre" (159). Auken's account explains the central role of expectations in recognizing genres, from rather simple to more complex cases. 
We wish to focus on those moments when interpretation of genre, and the commonly tacit assessments made, fail as genre users move and are moved into a new genre space. To illustrate our argument, we now turn to recent efforts to communicate about climate change research online using the social media platform Twitter.

\subsection{AltGov Twitter and Resistance Genre Work}

It was shortly after the inauguration of the $45^{\text {th }}$ President of the United States that the climate change page on WhiteHouse.gov was removed, and days later the US Environmental Protection Agency was instructed to remove their page on climate change (Davenport, 2017). Then, following the $45^{\text {th }}$ POTUS's claim that his audience was the largest on record, The National Parks Service tweeted comparative photos of the $44^{\text {th }}$ and $45^{\text {th }}$ POTUS' inauguration audiences. During this time, much concern and debate surrounding the new administration's plans for science-focused agencies and science funding circulated. Web pages related to climate change were taken down, and concerned scientists wondered what the meaning of these actions might be. Soon after a gag order was applied to numerous US agencies that operate under the Department of Interior (Revesz, 2017). Amidst concerns about silencing the National Parks Services, an unlikely source, began tweeting climate change facts. South Dakota's Badlands National Park used their Twitter presence (@BadlandsNPS) as a site of protest with a series of messages sharing facts about anthropogenic climate change: “The preindustrial concentration of carbon dioxide in the atmosphere was 280 parts per million (ppm). As of December 2016, 404.93 ppm', "Today, the amount of carbon dioxide in the atmosphere is higher than at any time in the last 650,000 years. \#climate," "Flipside of the atmosphere; ocean acidity has increased 30\% since the Industrial Revolution. 'Ocean Acidification' \#climate \#carboncycle,” and "Burning one gallon of gasoline puts nearly 20lbs of carbon dioxide into our atmosphere. \#climate” (qtd. in Reilly, 2017).

Characterizing typical tweets from @BadlandsNPS helps illustrate the significance of these four tweets to our argument here. Although we wish to provide some description of the common content and form of tweets, we do not want to make claims about their genre status. Indeed, not making such claims is central to our argument. Because the content and form of tweets evolves rather quickly we might find protogenres of science communication - or "genre candidates" (Gregersen, 2015) - but more important than a system of classification is acknowledging that there is some genre activity occurring. Put another way, although it may be difficult, as Miller and Shepherd (2009) found, to trace the rapid evolution of online genres of communication as they seem to "speciate," we can acknowledge genre-ing activities that help audiences understand and navigate the information they encounter in web-based media environments. Reviewing tweets from @BadlandsNPS over a year (January 2017 - January 2018), many posts feature photographs of the geography or photographs of wildlife, 
with an accompanying textual description or quotation. Occasional archival photos or photos of visitors are included, notes about events or changes to operating hours, or facts about wildlife (e.g., the species of ferrets living in the area) or geography and habitat (e.g., sod tables or the biological soil crust), or quotations without accompanying photos, and there are also the occasional retweets (sharing messages that others originally posted). Climate change facts may appear to be a rather significant departure from the normal patterns of activity from @BadlandsNPS, although notably, in early January 2017, a number of tweets were made about climate change facts, using the hashtag \#Climate. It was the series of tweets described above, posted on January $24^{\text {th }}, 2017$, that generated attention due to the gag order - it was a kairotic moment for climate change fact tweets (King, 2017). Soon after the tweets were posted, they were deleted, the press reported a statement from the National Park Service that a former employee unauthorized to use the account had shared these messages (Diaz, 2017).

Emerging from these tweets and the surrounding media attention, so-called AltGov Twitter accounts began to appear, such as @AltNatParkSer, and their authors claimed either to be involved with government agencies or more broadly as sympathizers with the cause. What seemed to be the cause? Political resistance to a new administration may seem the obvious social action these accounts hoped to achieve, but we argue many are positioned specifically as a defense of science, and quickly adopted the conventional form of the @BadlandsNPS account. However, @BadlandsNPS's use of climate change facts in response to a political exigence shifts the meaning of "the facts" insofar as they become (further) politically charged. What appears to be genred activity of simply reporting scientific information, then, has a rather different valence.

To understand more broadly how downstream accounts were influenced by the @BadlandsNPS's tweets, examining additional Twitter feeds provides further evidence. Since it is difficult to know who is behind a Twitter account, and indeed if they are a scientist, expert, or some other individual with the credibility to speak on some matter, the fact-checking website Snopes has worked to verify some of the Twitter accounts that emerged following the @BadlandsNPS's tweets. Notably, what they are able to verify is that the individual, or some of the individuals maintaining the accounts "has a legitimate connection to what they're posting about" (Binkowski, 2017). Table 1 provides an overview of the accounts verified by Snopes, and on their website, an up-to-date spreadsheet is available. 
Tab. 1: Snopes List of Verified Accounts

\begin{tabular}{llll} 
@ActualEPAFacts & @alt_kellyanne_ & @BadHombreNPS & @DeepStateRogue \\
\hline @Alt_4nTrade & @Alt_Labor & @knot4sharing & @AltScalesOfJust \\
\hline @AltArmedForces & @alt_labor_me & @RogueEPAStaff & @altEPAR9 \\
\hline @alt_BaldEagle & @alt_lawyer & @NastyWomenofNPS & @altDoD_ \\
\hline @altDIA & @AltLofC & @AltNMFS & @alt_localgov \\
\hline @altEPASmrtGrwth & @AltMtRainier & @altSmithsonian & \\
\hline @AltGS_Rocks & @AltNatSecAgency & @altUSNPS & \\
\hline @altHouseScience & @alt_uscbp & @TheRogueArkie & \\
\hline @alt_jabroni & @altUSPressSec & @AltYelloNatPark & \\
\hline @EducatorsResist & @AltWASONPS & @AngrierWHStaff &
\end{tabular}

Some accounts in this list tweet about climate change, including @AltArmedForces, which, during a cold spell in early 2018, tweeted, "The same people saying climate change is a myth because it is cold outside this week must also believe there is no drought anywhere in the world because it rained at their house today. \#ClimateChange” (@AltArmedForces, 2018). Singular data points, anecdotes from personal experience, and generalization based on these experiences is critiqued in this tweet as a reminder that scientific work is based on objective, data-driven evidence. The tweet critiques those opposing climate change research findings on the basis of personal opinion, and the formulation of the tweet reveals how the shift from empirical evidence to personal experience aids in the politicization of climate science.

Accounts identifying with science-focused agencies, such as the Environmental Protection Agency, provide further illustrative cases. Consider @ActualEPAFacts, which has a short biography with the following text: "\#AltGov: When the "elected" government lets you down, turn to us. We've got your back America” (@ActualEPAFacts, 2018). @ActualEPAFacts employs suggestive scare quotes and attempts to align themselves with the disenfranchised, further supported by their current Twitter banner, which reads "A Blue Congress Will Impeach" (blue is a colour aligned with the US Democratic party). Indeed, the account tweets a range of political messages, for example, the following selection of tweets:

@ActualEPAFacts 2 Jan 2018 More Trump tweeting about his great big "nuclear button" should be the HARD LINE for every American that cares about this country. Trump is a danger to us all. \#Impeach45 @ActualEPAFacts 19 Dec 2017 More The United States of America is now in the hands of criminals. 2018 is our last chance to save this country... 
@ActualEPAFacts 9 Nov 2017 More One year ago today we woke up to headlines we thought we'd never see. We've come a long way since then. We CAN make a difference. One year from now we will be celebrating a blue House and Senate.

These tweets have very little relation to the EPA in particular and certainly concern the broader current political situation. Although there are some tweets about climate change:

@ActualEPAFacts 26 Jan 2017 Climate change is the greatest global threat to coral reef ecosystems. Check out @noaaocean’s graphic for more info. \#climatechange [omitted a graphic]

As well, interestingly, a specific claim that science is not a partisan political issue:

@ActualEPAFacts 20 Feb 2017 More "Science is not Democratic or Republican, progressive or conservative. Science is science.” Wise words from @SenSanders \#sciencenotsilence

And a rather ominous message about the significance of science in our lives:

@ActualEPAFacts 25 Jan 2017 “WHEN THE VOICES OF SCIENTISTS ARE NOT HEARD, THERE IS A PRICE TO PAY.” [quotation marks and capitalization original]

Political messaging is clear even in the name of some "alt gov" Twitter accounts, such as the "@BadHombreNPS" account. The 45 and the overt racism of the term in political discourse made its way into the naming of an AltGov Twitter account, one also signaling solidarity with the National Parks Service (NPS). Their Twitter biography further clarifies their vantage: "Unofficial feed of Badlands NP. Protecting rugged scenery, fossil beds, 244,000 acres of mixed-grass prairie \& wildlife from two-bit cheetoh-hued despots” (@BadHombreNPS, 2018).

Among the AltGov accounts, @AltYelloNatPark frames itself directly, as both scientists and activists, writing they are: "An unofficial group of employees scientists and activists, in and around Yellowstone national park. We will try and keep you informed, when others can't". ${ }^{3}$ Tweets include mention of the so-called "flat earth" movement, current political events, tweets about conservation, and the value of national parks. Others recognize exactly the political melee they are enmeshed within, including @altHouseScience, "Run by PhD-holding, peer-review loving, nongov't members of \#TheResistance. Providing science commentary. DM to get involved. Not the official @HouseScience", who commented "Science is not above the fray of politics" (@altHouseScience, 2017).

Although it may appear that tweeting scientific facts or information is a genred activity online, what we have suggested here is that the configuration of media, public audiences, partisan political narratives in the public discourse sphere, and the norms

3 https://twitter.com/AltYelloNatPark. 
and values of scientific discourse communities function in such a way that what may have once been a genre of science communication has shifted into a partisan political typification. Tweets about climate change may sometimes serve to inform, but they now also, in their uptake by rogue Twitter accounts, respond to a rhetorical situation markedly different. Rather than communicating with a public that is unaware of these facts or who may simply be interested in the science, these rogue Twitter accounts are responding to a rhetorical situation defined by partisan politics at the highest national level in the United States.

Rising temperatures, ocean acidification, and a laundry list of other scientific facts provide the basis for scientists' understanding that climate change is happening and that humans play a significant role in that phenomenon. There is a practical problem with the approach to disseminating pure, apolitical information: the moment this information moves into broader public discourses, it participates in those already-established norms and conventions. Scientists cannot, any more than any other group, create a discourse sphere with broad, public audiences that will simply play by the rules of discourse in scientific professions, even if public audiences wanted to play by those rules.

\subsection{Final Remarks}

Genre theory helps us interrogate the ways in which the movement of genred tweets sharing climate change facts give way to more overtly politicized climate change arguments, a kind of speciation of scientific tweets communicating climate change research and science more broadly. For supporters, politicized tweets about science seem to function, ironically, to suggest that science will not bow to partisan political concerns. Science has the facts and scientists will share those facts, directly and without the kinds of manipulations partisan political discourses engage. Although this is a noble aspiration, it is unfortunately a naive understanding of the discourse sphere scientists are entering.

What is at stake for researchers communicating about climate change is the very message they hope to deliver. Twitter reveals how the rapid adoption of new media forms for communication of complex research can be challenging and can even be co-opted by those with adversarial positions. Genre theory can help us explore and explain the challenges in new media forms by identifying where norms, conventions, and expectations in different discourse communities appear to be incommensurable - and, importantly, where they are influential.

Devitt (this volume) explores the different forms of genre work we might conduct when deploying genres for social action. One form of generic resistance she illustrates is taken from scientific spheres of discourse. "Scientists," she writes, "report their results in scientific articles rather than news reports not only because that's the norm but because the genre fits their values and worldview," and as such they 
may not choose to participate in more popular forms of writing (Devitt, this volume). The challenge for scientists is that when they "venture into other genres to reach a broader audience, they can meet both their own and readers' resistance” (Devitt, this volume). Importantly, we do not wish to suggest that engagement in public and/or online spheres of discourse are problematic. Rather, we wish to underscore, to echo Devitt once more, "Genre matters." Genre awareness matters crucially in rapidly evolving online spheres of discourse, where genres routinely evolve into new forms or may take on hybrid forms, because with this increasing complexity in the genres we navigate, there are greater opportunities for a rhetorical misstep. For scientists communicating about climate change, the stakes are high. Thus, it is vital that we continue the conversation about emerging rhetorical situations in online environments with scientists and researchers using web-based genres for social actions. After all, this case reminds us - in contrast to @ActualEPAFacts' argument - science is never simply science, particularly when it engages actively with general publics in social media spaces. Instead, as @altHouseScience writes, "Science is not above the fray of politics.”

\section{References}

@ActualEPAFacts (2017, January 25). “WHEN THE VOICES OF SCIENTISTS ARE NOT HEARD, THERE IS A PRICE TO PAY.” [Twitter Post]. Retrieved from https://twitter.com/actualepafacts/ status/824443506894708736.

@ActualEPAFacts (2017, January 26). "Climate change is the greatest global threat to coral reef ecosystems. Check out @noaaocean's graphic for more info. \#climatechange” [Twitter Post]. Retrieved from https://twitter.com/ActualEPAFacts/status/824665179778641920.

@ActualEPAFacts (2017, February 20). "Science is not Democratic or Republican, progressive or conservative. Science is science.” Wise words from @SenSanders \#sciencenotsilence” [Twitter Post]. Retrieved from https://twitter.com/actualepafacts/status/833804675258396673.

@ActualEPAFacts (2017, November 9). “One year ago today we woke up to headlines we thought we'd never see. We've come a long way since then. We CAN make a difference. One year from now we will be celebrating a blue House and Senate." [Twitter Post]. Retrieved from https:// twitter.com/ActualEPAFacts/status/928630487253471232.

@ActualEPAFacts (2017, December 19). "The United States of America is now in the hands of criminals. 2018 is our last chance to save this country..." [Twitter Post]. Retrieved from https:// twitter.com/ActualEPAFacts/status/943321341419192320.

@ActualEPAFacts (2018). Biography. [Twitter Account]. Retrieved from https://twitter.com/ actualepafacts.

@ActualEPAFacts (2018, January 2). “Trump tweeting about his great big “nuclear button” should be the HARD LINE for every American that cares about this country. Trump is a danger to us all. \#Impeach45." [Twitter Post]. Retrieved from https://twitter.com/ActualEPAFacts/ status/948411487097360384.

@AltArmedForces (2018, January 3). “The same people saying climate change is a myth because it is cold outside this week must also believe there is no drought anywhere in the world because it rained at their house today. \#ClimateChange" [Twitter Post]. Retrieved from https://twitter. com/AltArmedForces/status/948595409651404801. 
@altHouseScience (2017, January 9). “Science is not above the fray of politics.” [Twitter Post]. Retrieved from https://twitter.com/altHouseScience/status/950398808265056256.

@AltYelloNatPark (2018). Biography. [Twitter Account]. Retrieved 2019, March 7, from https://twitter. com/altyellonatpark?lang=en.

@BadHombreNPS (2018). Biography. [Twitter Account]. Retrieved from https://twitter.com/ badhombrenps?lang=en.

Andersen, J. (2016). Genre, the organization of knowledge and everyday life. In Proceedings of the Ninth International Conference on Conceptions of Library and Information Science, Uppsala, Sweden, June 27-29, 2016 Information Research, 22(1) paper colis1647. Retrieved from http://InformationR.net/ir/22-1/colis/colis1647.html (Archived by WebCite ${ }^{\circledR}$ at http://www. webcitation.org/6olgtXunh).

Andersen, T.H., \& van Leeuwen, T.J. (2017). Genre crash: The case of online shopping. Discourse, Context \& Media, 20, 191-203. doi:10.1016/j.dcm.2017.06.007.

Auken, S. (2015). Genre and interpretation. In S. Auken, P.S. Lauridsen, \& A.J. Rasmussen (Eds.), Genre and ... (154-183). Copenhagen: Ekbátana (Copenhagen Studies in Genre; vol. 2).

Bazerman, C. (1988). Shaping written knowledge. Madison, WI: The University of Wisconsin Press.

Binkowski, B. (2017, April 24). Twitter's alts and rogues. Snopes.com. Retrieved from https://www. snopes.com/2017/06/01/alts-and-rogues/.

Burkeman, 0. (2003, March 4). Memo exposes Bush's new green strategy. The Guardian. Retrieved from https://www.theguardian.com/environment/2003/mar/04/usnews.climatechange.

Caple, H., \& Knox, J.S. (2017). Genre (less) and purpose (less): Online news galleries. Discourse, Context \& Media, 20, 204-217.

Ceccarelli, L. (2011). Manufactured scientific controversy: Science, rhetoric, and public debate. Rhetoric \& Public Affairs, 14(2), 195-228. doi:10.1353/rap.2010.0222.

Davenport, C. (2017, January 20). With Trump in charge, climate change references purged from website. New York Times. Retrieved from https://www.nytimes.com/2017/01/20/us/politics/ trump-white-house-website.html.

Diaz, D. (2017, January 24). Badlands National Park deletes tweets on climate change. CNN. Retrieved from www.cnn.com/2017/01/24/politics/badlands-tweets-climate-change/index. html.

Fahnestock, J. (1986). Accommodating science: The rhetorical life of scientific facts. Written Communication, 3(3), 275-296.

Giddens, A. (1984). The constitution of society: Outline of the theory of structuration. Berkeley: University of California Press.

Giltrow, J., \& Stein, D. (Eds.). (2009). Genres in the Internet: Issues in the theory of genre. Amsterdam, The Netherlands: John Benjamins Publishing Company.

Gregersen, F. (2015). Genre and everyday conversation. In S. Auken, P.S. Lauridsen, \& A.J. Rasmussen (Eds.), Genre and ... (56-98). Copenhagen: Ekbátana (Copenhagen Studies in Genre; vol. 2).

Kelly [now Mehlenbacher], A.R., \& Miller, C.R. (2016). Intersections: Scientific and parascientific communication on the Internet. In A.G. Gross \& J. Buehl (Eds.), Science and the Internet: Communicating knowledge in a digital age (221-245). Amityville, NY: Baywood Press. doi:10.2190/SCIC11.

King, L. (2017, January 24). EPA 'pause' on public communications fuels wider alarm about openness. USA Today. Retrieved from https://www.usatoday.com/story/news/politics/2017/01/24/ epa-pause-public-communications-fuels-wider-alarm-openness/97009206/.

Lewis, J. (2016). Content management systems, Bittorrent trackers, and large-scale rhetorical genres: Analyzing collective activity in participatory digital spaces. Journal of Technical Writing and Communication, 46(1), 4-26. doi:10.1177/0047281615600634. 
Mellon, J., \& Prosser, C. (2017). Twitter and Facebook are not representative of the general population: Political attitudes and demographics of British social media users. Research \& Politics, 4(3). doi:2053168017720008.

Miller, C.R. (1984). Genre as social action. Quarterly Journal of Speech, 70(2), 151-167.

Miller, C.R. (2017). Where do genres come from? In C.R. Miller \& A.R. Kelly [now Mehlenbacher] (Eds.), Emerging genres in new media environments (1-34). London: Palgrave Macmillan. doi:10.1007/978-3-319-40295-6_1.

Miller, C.R., \& Kelly [now Mehlenbacher], A.R. (Eds.). (2017). Emerging genres in new media environments. London: Palgrave Macmillan.

Miller, C.R., \& Shepherd, D. (2004). Blogging as social action: A genre analysis of the weblog. In L. Gurak et al. (Eds.), Into the blogosophere: Rhetoric, community, and culture of weblogs. University of Minnesota Libraries.

Miller, C.R., \& Shepherd, D. (2009). Questions for genre theory from the blogosphere. In J. Giltrow \& D. Stein (Eds.), Genres in the Internet: Issues in the theory of genre (263-290). Amsterdam, The Netherlands: John Benjamins Publishing Company.

Oreskes, N. (2004). The scientific consensus on climate change. Science, 306(5702), 1686. doi:10.1126/science.1103618.

Oreskes, N. (2010). Merchants of doubt. New York: Bloomsbury Press.

PEW Research Center (2016a, October 4). The politics of climate. Pew Research Center. Retrieved from http://www.pewinternet.org/2016/10/04/the-politics-of-climate/.

PEW Research Center (2016b, November 11). Social media update 2016. Pew Research Center. Retrieved from http://www.pewinternet.org/2016/11/11/social-media-update-2016/

PEW Research Center (2017). Social media fact sheet. Pew Research Center. Retrieved from http:// www.pewinternet.org/fact-sheet/social-media/.

PEW Research Center (2018, March 1). Social media use in 2018. PEW Research Center. Retrieved from http://www.pewinternet.org/2018/03/01/social-media-use-in-2018/.

Pflugfelder, E.H. (2017). Reddit's "Explain Like l'm Five": Technical descriptions in the wild. Technical Communication Quarterly, 26(1), 25-41.

Reiff, M.J., \& Bawarshi, A. (Eds.). (2016). Genre and the performance of publics. Logan: Utah State University Press.

Reilly, K. (2017, January 24).A rogue national park is tweeting out climate change facts in defiance of Donald Trump. Time Magazine. Retrieved from www.time.com/4645927/badlands-nationalpark-climate-change-tweets/.

Revesz, R. (2017, January 27). Donald Trump personally called the national park service director about those Inauguration photos. Independent. Retrieved from https://www.independent. co.uk/news/world/americas/donald-trump-national-park-service-michael-reynolds-inauguration-crowd-size-photos-proof-a7548601.html.

Schryer, C.F. (1993). Records as genre. Written Communication, 10(2), 200-234.

Sherlock, L. (2009). Genre, activity, and collaborative work and play in World of Warcraft: Places and problems of open systems in online gaming. Journal of Business and Technical Communication, 23(3), 263-293.

Smart, G. (2016). Discourse coalitions, science blogs, and the public debate over global climate change. In M. Reiff \& A. Bawarshi (Eds.), Genre and the performance of publics (157-177). Logan: Utah State University Press. doi:10.7330/9781607324430.c008.

Supran, G., \& Oreskes, N. (2017). Assessing ExxonMobil's climate change communications (1977-2014). Environmental Research Letters, 12, 1-18. doi:10.1088/1748-9326/aa815f.

Yates, J., \& Orlikowski, W.J. (1992). Genres of organizational communication: A structurational approach to studying communication and media. Academy of Management Review, 17(2), 299-326. 
Wickman, C. (2016). "Learning to share your science": The scientific notebook textual object and dynamic rhetorical space. In A.G. Gross \& J. Buehl (Eds.), Science and the Internet: Communicating knowledge in a digital age (11-32). Amityville, NY: Baywood Press.

Zappavigna, M., \& Zhao, S. (2017). Selfies in 'mommyblogging': An emerging visual genre. Discourse, Context \& Media, 20, 239-247. doi:10.1016/j.dcm.2017.05.005. 